\title{
Molecular characterization of the Central Repeat Region of Plasmodium falciparum Circumsporozoite Gene among Selected Malaria Patients in Omdurman, Sudan
}

\author{
Ali Mussa \\ Omdurman Islamic University \\ Mustafa Talib \\ Omdurman Islamic University \\ Zeehaida Mohamed \\ Universiti Sains Malaysia \\ Khalid Hajissa ( $\sim$ khalid541983@yahoo.com ) \\ Omdurman Islamic University https://orcid.org/0000-0002-1725-6702
}

Research article

Keywords: Circumosporozoite, Central repeats, Polymorphism, Plasmodium falciparum, Omdurman, Sudan

Posted Date: July 5th, 2019

DOI: https://doi.org/10.21203/rs.2.11002/v1

License: (c) (1) This work is licensed under a Creative Commons Attribution 4.0 International License.

Read Full License 


\section{Abstract}

Background Malaria is considered one of the most life-threatening diseases due to its raised morbidity and mortality rate, especially in developing countries including Sudan. Plasmodium falciparum remains the most fatal species associated with severe illness as well as high mortality rate. This study aimed to investigate the genetic polymorphism within P. falciparum circumsporozoite gene central repeat region, among selected Sudanese malaria patients. Methods This was a cross-sectional study conducted in Omdurman; Sudan, during the period of Sep 2017 to Feb 2018. Fifty-nine suspected malaria patients were enrolled in this study. Blood samples were collected and screened using rapid diagnostic tests (RDT) and DNA was extracted for Parasite molecular identification using nested PCR (nPCR). Subsequently, PCR positive samples were subjected to central repeat amplification. Results The rapid diagnostic tests detected 78\% (46/59) P. falciparum positive cases, 6.8\% (4/59) were co-infected with P. falciparum and P. vivax, and 15.3\% (9/59) were negative. In contrast, using nPCR showed 44.1\% (26/59) patients were P. falciparum positive and 55.9\% (33/59) were negative. For the cs central repeat genotyping, only 14 amplicons were obtained with no clear variation in band size. Conclusion The study revealed no clear variation in band sizes, indicating for the absence of variation in repeat length, however, the samples need to be subjected for DNA sequence analysis to identify the most common variants as well as for better understanding of how these variants will effect on the performance of the RTS.S malaria vaccine.

\section{Background}

Malaria is one of the most important infectious diseases associated with major public health problems in tropical and subtropical countries due to its high morbidity and mortality rates. Five different Plasmodium species have been correlated with the malaria illness in human, among them $P$. falciparum is the most fatal species distributed mostly in Africa [1]. Globally, mortality reached $\sim 429,000-730,500$ in 2015 and $2016[2,3]$. In sub-Saharan Africa, about $80 \%$ of the malaria cases and $98 \%$ of death is attributed to $P$. falciparum $[2,3]$. In Sudan, more than $95 \%$ of the cases are caused by $P$. falciparum. Recently, P. vivax cases have been reported from different clinical centers as well [4].

Thus developing an effective and long lasting malaria vaccine would provide a supplementary weapon for malaria control. Consequently, vaccine development has become a top priority in the agenda of public health program [5] (Nega et al., 2016). However, only by 2017, the World health organization has given the permission for the RTS.S/AS01 vaccine to proceed for a pilot implementation study in Ghana, Kenya, and Malawi, therefore, it is considered the most promising malaria vaccine [6].

RTS, S/AS01 is composed of a part of central repeat region and the C-terminal T cell antigenic determinant of $P$. falciparum circumsporozoite protein (CSP) conjugated with Hepatitis B surface antigen enhanced with the adjuvant system (AS01), CSP is the most abundant protein on the sporozoite surface and is composed of a central repeat region with a common motif NANP (N, Asparagine; A, Alanine; N, Asparagine and $\mathrm{P}$, Proline) acting as $\mathrm{B}$ cell epitopes and two flanking non-repeated region, although 
variable numbers have been identified for central motifs but only 19 were incorporated in vaccine design $[7,8]$.

However, RTS.S/AS01 vaccine showed only $27-46 \%$ efficacy in third phase clinical trial $[3,5]$, therefore, many questions have been raised regarding the vaccine efficiency, possibly genetic polymorphism within central repeat region which generate a variable number of repeat motif within different geographical locations as well as between two individual within the same region might be influencing the vaccine efficacy $[3,8,9,10]$. Therefore, investigations within this region in different geographical locations might assist in illustrating if these alternative motifs will compromise the RTS, S vaccine when it is applied globally.

Therefore, the current study was designed to investigate the genetic polymorphism within $P$. falciparum cs central repeat region to identify the most common variants along with the repeat length among natural Sudanese parasitic isolates.

\section{Methods}

\section{The study area, population and Sample Collection}

The study was conducted in Omdurman, Sudan. (15.64 latitudes, 32.48 longitudes, 391 meters above sea level). Samples were collected during the time from Sep 2017 to Feb 2018 from different clinical centers.

The study populations were the patients requested for malaria BF or ICT tests. A total of 59 participants were recruited for this study. The suspected individuals were asked to assign a written informed consent before $3 \mathrm{ml}$ of peripheral blood were collected in a clean sterile EDTA vacutainer, and the blood was screened for P. falciparum using Malaria P.f / P.v Rapid Test Cassette kit (Biotech, Germany).

\section{DNA Extraction}

The genomic DNA was isolated from $300 \mu$ of blood samples using G-DEX ${ }^{\mathrm{TM}} \mathrm{Illb}$ Genomic DNA Extraction Kit for Blood (iNtRON, South Korea), the purity and quantity of the obtained DNA was measured using NanoDrop ${ }^{\circledR}$ (NanoDrop Technologies, USA), and stored at $-20^{\circ} \mathrm{C}$ until be used for PCR assays.

\section{Malaria parasites Molecular Identification}

The molecular identification was performed using nested PCR assay, the genus and species were detected by applying three oligonucleotides designed previously by Snounos in 1996 [11] for small subunit ribosomal RNA (ssrRNA). For genus specification (nset-1) the reaction mixture was prepared with final volume $20 \mu$ l by adding $4 \mu \mathrm{l}$ of $5 x$ HOT FIREPol Blend Master Mix (Solis BioDyne, Denmark), 1.5 $\mu \mathrm{l}$ $(0.75 \mu \mathrm{M})$ of each primer of genus-specific (table 1 ) and $2 \mu$ l from genomic DNA and $11 \mu \mathrm{lddH} \otimes \mathrm{O}$. The PCR cycling conditions were adjusted as $95^{\circ} \mathrm{C}$ for $4 \mathrm{~min}$ as initial denaturation, $95^{\circ} \mathrm{C}$ for $30 \mathrm{sec}, 49^{\circ} \mathrm{C}$ for $30 \mathrm{sec}$, 
$72^{\circ} \mathrm{C}$ for $60 \mathrm{sec}$, for $35 \mathrm{cycles}$ and $72^{\circ} \mathrm{C}$ for $5 \mathrm{~min}$ as end cycle. For species identification (nest-2) two species-specific primers were used one for $P$. falciparum and the second for $P$. vivax (Table 1) following the same approach as nest- 1 condition for the reaction mixture preparation as well as PCR condition except for the product of nest-1 was used instead of genomic DNA and the annealing temperature was modified to $60^{\circ} \mathrm{C}$ for $60 \mathrm{sec}$.

\section{cs gene central repeat genotyping}

The central repeat region of the cs gene was amplified using nPCR, the reaction was performed using two sets of oligonucleotides, one targeted the whole gene, and the second was specified for the central repeat region as described previously by Gandhi in 2014. For nest-1 The reaction mixture was prepared similarly to the genus-specific PCR reaction, except oligonucleotides for whole cs gene amplification was used (Table 1) and the reaction was performed under the condition set as $95^{\circ} \mathrm{C}$ for $4 \mathrm{~min}$ as the starting denaturation, $95^{\circ} \mathrm{C}$ for $30 \mathrm{sec}, 55^{\circ} \mathrm{C}$ for $30 \mathrm{sec}, 72^{\circ} \mathrm{C}$ for $60 \mathrm{sec}$ for 35 cycles and $72^{\circ} \mathrm{C}$ for 5 min was used as prolonged extension.

The second reaction (nest-2) was performed using specific oligonucleotide for the central repeat region (table 1), Again the reaction mixture was prepared following the same approach as for genus amplification reaction except $0.5 \mu \mathrm{l}(0.25 \mu \mathrm{M})$ of $c s$ central repeat specific oligonucleotide and $0.5 \mu \mathrm{l}$ of $c s$ nest-1 product were used, the reaction condition was specified as following, $95^{\circ} \mathrm{C}$ for $4 \mathrm{~min}$ for initial denaturation, $95^{\circ} \mathrm{C}$ for $30 \mathrm{sec}, 54^{\circ} \mathrm{C}$ for $30 \mathrm{sec}, 70^{\circ} \mathrm{C}$ for $90 \mathrm{sec}$ and final extension $72^{\circ} \mathrm{C}$ for $7 \mathrm{~min}$. for 30 cycles. All PCR products were resolved on $1.5 \%$ agarose gel.

\section{Statistical analysis}

The collected data was entered into the Statistical Package for the Social Sciences (SPSS), version 23 (SPSS Inc., USA). Then the descriptive statistic was performed to measure the frequency distribution of variants.

\section{Results}

A total of 59 malaria-suspected patients were enrolled in this study. Among them, 54.2\% (32/59) were males while $45.8 \%$ (27/59) were females. They have ages ranging from 17 to 67 years old, with a mean age of 29.19 years old. All the blood samples were screened for the presence of malaria parasite using ICT as well as PCR. The results of the ICT analysis indicated that $78 \%(46 / 59)$ were infected with $P$. falciparum, 6.8\% (4/59) were co-infected with $P$. falciparum and $P$. vivax and $15.3 \%(9 / 59)$ were negative as shown in (Figure 1). On the other hand, molecular diagnosis targeting ssrRNA using nested PCR assay indicate that $44.1 \%(26 / 59)$ were positive and $55.9 \%$ (33/59) were negative as illustrated in (Figure 2, 3).

All PCR positive samples were subjected for further analysis to identify the molecular variants within the central repeat region based on the PCR amplicon size and the results showed that the gene was amplified 
from $53.8 \%(14 / 26)$ with no variation as illustrated in (Figure 4), as their length was corresponding to the reference length which retrieved from the gene-bank, while no amplicons were shown for $46.2 \%(12 / 26)$.

\section{Discussion}

Considerable efforts have devoted to come-out with a highly effective as well as long-lasting vaccine. Several gene candidates were explored and well-studied. A great advancement has been achieved through different vaccine development approaches varying from a genetically or chemically attenuated vaccines as well as vector-borne by utilizing adenovirus or subunit vaccines $[5,6]$, interestingly, all these vaccines are under clinical trial ranging from pre-clinical to stage four clinical trials.

Despite the improvement in acquiring potential vaccine candidate, major scientific obstacles remain as significant challenges for malaria vaccine design and development. This includes: short-term protection, the route of administration either intravenously or intradermally, and the appropriate dosage that will elicit an effectively controlled immunity without harming the immunized individual, however, the most tedious issue is antigenic diversity which acts as a major obstacle toward vaccine development [6]. Antigenic polymorphism within the central region of the RTS,S has been considered as the most threatening element for its efficacy $[8,9$, and 10]. Therefore, the current study was aiming to identify the most prominent molecular variant within central repeat region along with their distribution for $P$. falciparum among the study participants of selected malaria patient in Omdurman, Sudan.

As the preliminary investigation for the parasite occurrence was achieved using two different diagnostic techniques a comparison has established between them, out of 50 positive $P$. falciparum mono-infection and co-infection only 20 samples were confirmed positive by nested PCR indicating for ICT test inefficiency, and this was comparable with study conducted in India where many cases were misdiagnosed by RDT [1]. Overall, this false positive result could be attributed to a recent antimalarial uptake and the presence of serum rheumatoid factor [12]. In this study, we postulated that many of the study participants might have received un-prescribe treatment as it is a common phenomenon among the study population, and also spontaneous resolution of untreated infections along with the persistent HRP2 in the circulation is relatively proposed as causative factor of this result, additionally, false positive could be due to heterophilic antibodies $[12,13]$. Also, storage condition could have a remarkable impact on the accuracy of the ICT performance [14], furthermore, PCR accuracy in identifying Plasmodium spp is directly rely on the quality of the extracted DNA, the reagents, and amplification condition [15].

In contrast, nested PCR showed high sensitivity over the ICT test as six out of nine negative ICT have been detected positive by $\mathrm{nPCR}$, and this might be attributed to the low level of parasitemia [16], also little expression of the target gene might decrease the threshold of the circulating antigen thus hinder their detection $[14,16]$. Conversely, hyperparasitemia would have a negative impact by causing antigenic overload which possibly influences parasite diagnosis [14]. Additionally, one sample was misdiagnosed as co-infected specimen by malaria ICT but confirmed as $P$. falciparum mono-infection when nPCR was 
applied, this observation is in line with the study conducted in India where ICT based in HRP2 failed to identify and distinguish between mono-infected $P$. falciparum cases and co-infected cases [1].

Likewise, the deletion within already applied gene segment for ICT diagnostic kits, which has been reported in different geographical regions such as; Eriteria [17], Peru [18], Colombia [19] for hrp2 will contributed to its inefficiency for malaria diagnosis [14], however, this could not be considered as main causes of false negative result in this study, due to the lack of information about the distribution of this phenomenon within the study area.

For cs central repeat region, only 14 amplicons were obtained with no clear variation was observe between them as illustrated with gel image in (Figure 4) this finding indicates for possibly no variation within repeat number among study participants which contradicts with several studies that showed a variable number of repeats based on nucleotide sequence analysis $[8,9,10]$. However, as the study is ongoing more details are prospected after achieving the sequence analysis that will give exact information about the sequence of the already obtained amplicons; Consequently, this result gives no clear explanation about the genetic diversity within this region for Sudanese selected isolates. However, this study has raised many questions expected to be answered in near future. As the study is progressing, the limitations such as a few sample size and DNA sequencing analysis will be covered for more insights about the studied region.

\section{Conclusions}

Plasmodium falciparum isolate from Sudanese selected patients indication for the absence of variation in repeat numbers. And the study wasn't able to identify the common molecular variants as well as their number due to lack of DNA sequencing analysis. And the study is foreseeing to obtain remarkable insights about cs central repeat among Sudanese patient as the study is still in progression.

\section{Abbreviations}

RDT, Rapid diagnostic tests; DNA, Deoxyribonucleic acid; nPCR, Nested Polymerase chain reaction; $C S$, Circumosporozoite gene; $P$. falciparum, Plasmodium falciparum; RTS.S/AS01, 'R' central repeat region of P. falciparum CSP, 'T' for the T-cell epitopes, 'S' for hepatitis B surface antigen (HBsAg), 'S' protein spontaneously assemble in 'RTS,S' particles, 'AS01' adjuvant system; NANP, N, Asparagine; A, Alanine and P, Proline; ssrRNA, small subunit ribosomal RNA; $\mu$ l, Microliter; $\mu \mathrm{M}$, Micro-molar; ddHखO, Double distil water; SPSS, Statistical Package for the Social Sciences; Kb, Kilo-base pair; bp, Base pair; ICT, Immunochromatographic test.

\section{Declarations}

\section{Ethical approval and consent to participate}


This study was ethically approved by the Ethical committee of the Research directorate, General Directorate of planning \& International Health, Federal Ministry of Health, Republic of Sudan. An informed consent has been signed from each participant or guardians before they provide their samples.

\section{Consent for publication}

Not applicable

\section{Availability of data and materials}

Any further requested information regarding the experimental and data analysis during the current study is available from the corresponding author on reasonable request.

\section{Competing interests}

The authors declare that they have no competing interests

\section{Funding}

This study was supported by the Grants of the Commission of Scientific Research and Innovation, Ministry of Higher Education and Scientific Research, Sudan, grant No. SRIC/2017/RP761.

\section{Authors' contributions}

MT was fully involved in all rounds of the study, including the study design, laboratory investigation during Molecular analysis, data analysis, interpretation, and write-up of the manuscript; AM was involved in Molecular investigation and statistical analysis of data, $\mathrm{KH}$ was involved in designing the study project and critically revised the manuscript. All authors read and approved the final manuscript.

\section{Acknowledgements}

I am sincerely grateful to Dr. Rania Baleela and Haseeba Saad for their contribution in final language check and editing. My gratitude also passes to the lab technicians Aisha Abdel Kaream and Abdel wahab Ibraheam for their assistance in sample collection and the study participants. I would like to express my thanks to Mr Ahamid El-gadam for his constructive ideas and comments during molecular analysis approach. Finally, I would like to express my gratitude to Ms. Amaal for her technical assistance.

\section{Authors' information}

${ }^{1}$ Genetics and Molecular Biology Laboratory, Department of Zoology, Faculty of Science, University of Khartoum, Khartoum, Sudan. ${ }^{2}$ Department of Zoology, Omdurman Islamic University, Omdurman, Sudan. ${ }^{3}$ Department of Medical Microbiology \& Parasitology, School of Medical Sciences, Universiti Sains Malaysia16150 KubangKerian, Kelantan, Malaysia. 


\section{References}

1. Siwal N, Singh US, Dash M, Kar S, Rani S, Rawal C, Singh R, Anvikar AR, Pande V, Das A. Malaria diagnosis by PCR revealed differential distribution of mono and mixed species infections by Plasmodium falciparum and P. vivax in India. PloS one. 2018 Mar 22;13(3)

1. World Health Organization. False-negative RDT results and implications of new reports of P. falciparum histidine-rich protein 2/3 gene deletions. World Health Organization; 2017.

2. Gosling R, von Seidlein L. The future of the RTS, S/AS01 malaria vaccine: an alternative development plan. PLoS medicine. 2016 Apr 12;13(4).

3. Suliman MM, Hamad BM, Albasheer MM, Elhadi M, Amin Mustafa M, Elobied M, Hamid MM. Molecular evidence of high proportion of Plasmodium vivax malaria infection in White Nile area in Sudan. Journal of parasitology research. 2016;2016.

4. Nega D, Alemu A, Tasew G. Journal of Bacteriology \& Parasitology. infection. 2016;13:17.

5. Coelho CH, Doritchamou JY, Zaidi I, Duffy PE. Advances in malaria vaccine development: report from the 2017 malaria vaccine symposium.

6. Bowman NM, Congdon S, Mvalo T, Patel JC, Escamilla V, Emch M, Martinson F, Hoffman I, Meshnick SR, Juliano JJ. Comparative population structure of Plasmodium falciparum circumsporozoite protein NANP repeat lengths in Lilongwe, Malawi. Scientific reports. 2013 Jun 17;3:1990.

7. Patel P, Bharti PK, Bansal D, Raman RK, Mohapatra PK, Sehgal R, Mahanta J, Sultan AA, Singh N. Genetic diversity and antibody responses against Plasmodium falciparum vaccine candidate genes from Chhattisgarh, Central India: implication for vaccine development. PloS one. 2017 Aug 7;12(8).

8. Gandhi K, Thera MA, Coulibaly D, Traore K, Guindo AB, Ouattara A, Takala-Harrison S, Berry AA, Doumbo OK, Plowe CV. Variation in the circumsporozoite protein of Plasmodium falciparum: vaccine development implications. PloS one. 2014 Jul 3;9(7).

10. Zeeshan M, Alam MT, Vinayak S, Bora H, Tyagi RK, Alam MS, Choudhary V, Mittra P, Lumb V, Bharti PK, Udhayakumar V. Genetic variation in the Plasmodium falciparum circumsporozoite protein in India and its relevance to RTS, S malaria vaccine. PLoS One. 2012 Aug 17;7(8).

11. Snounou G. Detection and identification of the four malaria parasite species infecting humans by PCR amplification. InSpecies Diagnostics Protocols 1996 (pp. 263-291). Humana Press.

12. Mouatcho JC, Goldring JD. Malaria rapid diagnostic tests: challenges and prospects. Journal of medical microbiology. 2013 Oct 1;62(10):1491-505.

13. Bell DR, Wilson DW, Martin LB. False-positive results of a Plasmodium falciparum histidine-rich protein 2-detecting malaria rapid diagnostic test due to high sensitivity in a community with fluctuating low parasite density. The American journal of tropical medicine and hygiene. $2005 \mathrm{Jul}$ 1;73(1):199-203.

14. World Health Organization. World malaria report 2017.

15. Kitchen AD, Chiodini PL. Malaria and blood transfusion. Vox sanguinis. 2006 Feb;90(2):77-84. 
16. Koita OA, Doumbo OK, Ouattara A, Tall LK, Konaré A, Diakité M, Diallo M, Sagara I, Masinde GL, Doumbo SN, Dolo A. False-negative rapid diagnostic tests for malaria and deletion of the histidinerich repeat region of the hrp2 gene. The American journal of tropical medicine and hygiene. 2012 Feb 1;86(2):194-8.

17. Menegon M, L'Episcopia M, Nurahmed AM, Talha AA, Nour BY, Severini C. Identification of Plasmodium falciparum isolates lacking histidine-rich protein 2 and 3 in Eritrea. Infection, Genetics and Evolution. 2017 Nov 1;55:131-4.

18. Gamboa D, Ho MF, Bendezu J, Torres K, Chiodini PL, Barnwell JW, Incardona S, Perkins M, Bell D, McCarthy J, Cheng Q. A large proportion of P. falciparum isolates in the Amazon region of Peru lack pfhrp2 and pfhrp3: implications for malaria rapid diagnostic tests. PloS one. 2010 Jan 25;5(1).

19. Solano CM, Okoth SA, Abdallah JF, Pava Z, Dorado E, Incardona S, Huber CS, de Oliveira AM, Bell D, Udhayakumar V, Barnwell JW. Deletion of Plasmodium falciparum histidine-rich protein 2 (pfhrp2) and histidine-rich protein 3 (pfhrp3) genes in Colombian parasites. PloS one. 2015 Jul 7;10(7).

\section{Tables}

Table 1 list of primers

\begin{tabular}{|c|c|c|c|}
\hline Specificity/reaction & Names & Sequence & Product size \\
\hline Plasmodium genus & rPLU5 & 5ロ-CTT GTT GTT GCC TTA AAC TTC-3ロ & $\sim 1.2 \mathrm{~Kb}$ \\
\hline Nest-1 & rPLU6 & 5ロ-TTA AAA TTG TTG CAG TTA AAA CG-3ロ & \\
\hline P. falciparum & rFAL1 & 5'-TTA AAC TGG TTT GGG AAA ACC AAA TAT ATT-3' & $205 \mathrm{~Pb}$ \\
\hline Nest-2 & rFAL2 & 5'-ACA CAA TGA ACT CAA TCA TGA CTA CCC GTC-3' & \\
\hline P. vivax & rVIV1 & 5'-CGC TTC TAG CTT AAT CCA CAT AAC TGA TAC-3' & $144 \mathrm{~Pb}$ \\
\hline Nest-2 & rVIV2 & 5'-ACT TCC AAG CCG AAG CAA AGA AAG TCC TTA-3' & \\
\hline \multirow[t]{2}{*}{ cs gene } & - & 5ロ-GTTGAGGCCTTTTCCAGGAATACCAG-3ロ & $\sim 1.3 \mathrm{~Kb}$ \\
\hline & & 5ロ-GTACAACTCAAACTAAGATGTGTTC-3 & \\
\hline \multirow[t]{2}{*}{ cs central repeat region } & - & 5ロ-TGGGAAACAGGAAAATTGG-3ロ & $\sim 702 \mathrm{~Pb}$ \\
\hline & & 5ロ-GCACTGTTGGCATTAGCATTT-3』 & \\
\hline
\end{tabular}

\section{Figures}




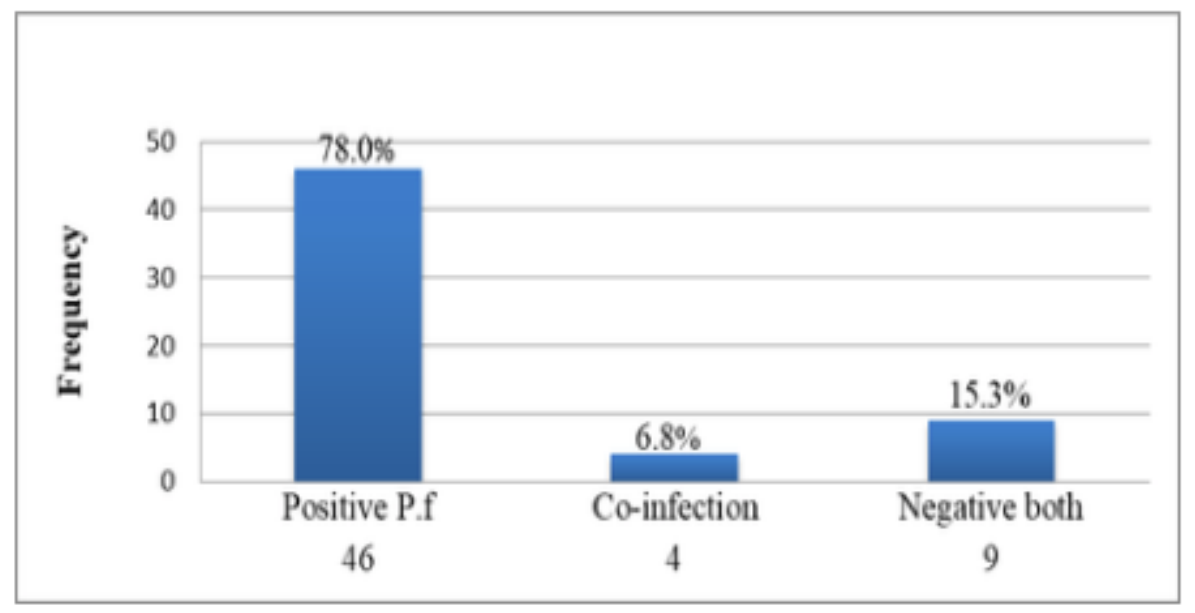

\section{Figure 1}

Screening of malaria infection using ICT test.

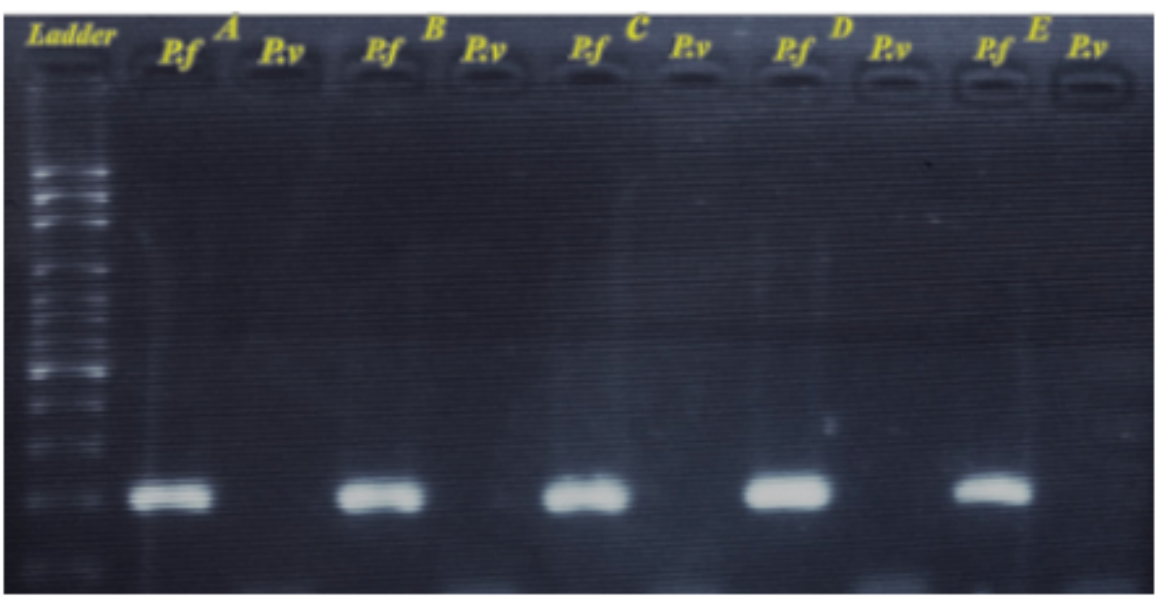

Figure 2

Identification of Plasmodium species by molecular diagnosis, Lane Ladder: DNA marker 100bp, Lane A-E: PCR amplicon ( 205bp) from different samples indicate for positive P.f and negative P.v.

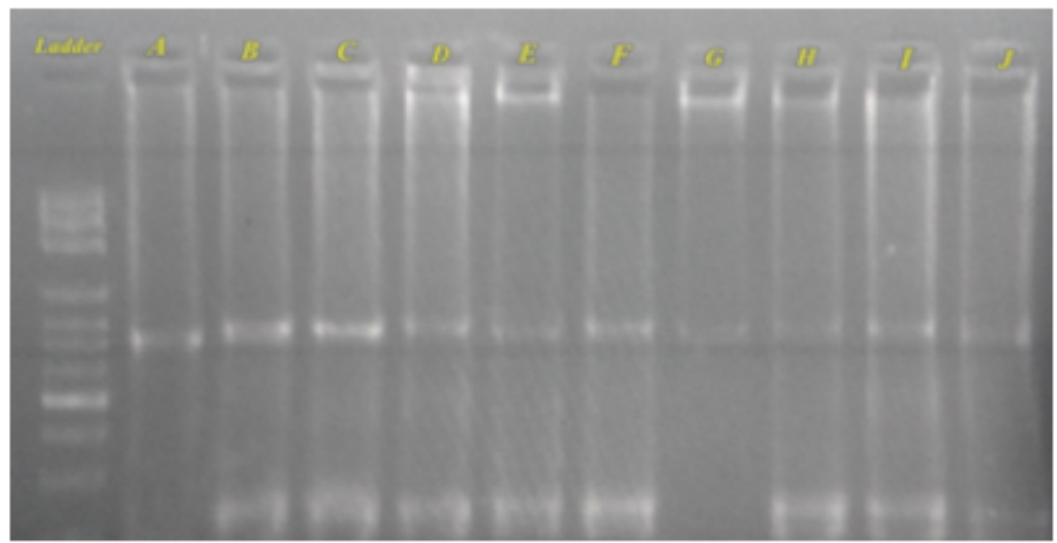


Figure 3

cs gene central repeat amplicons form different specimens showing no clear variation in band size within range $700 \mathrm{bp}$.

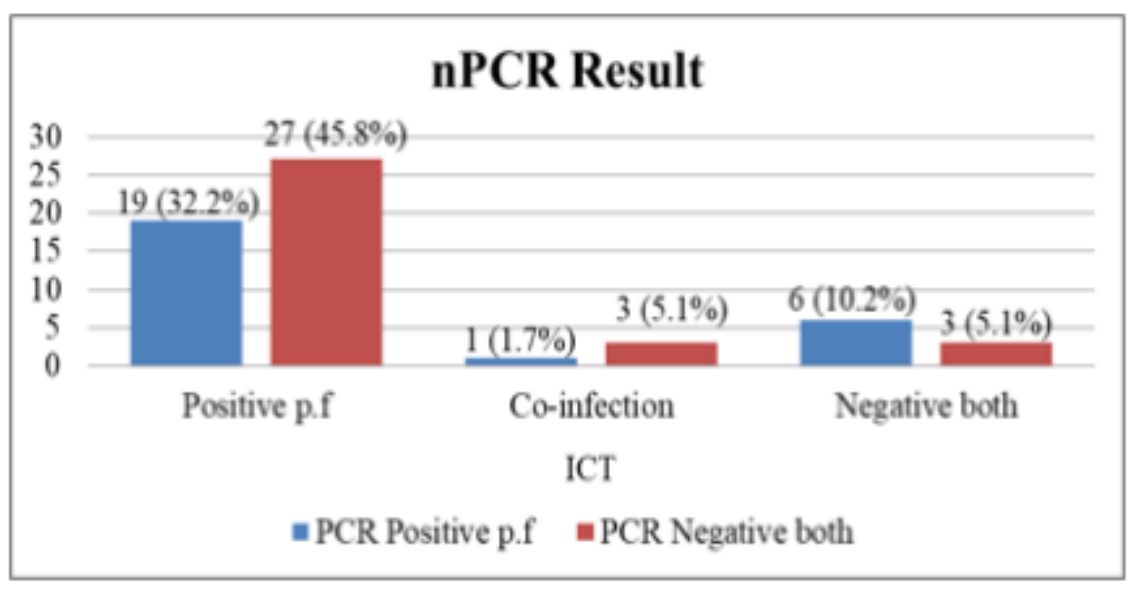

\section{Figure 4}

Overall views of P. falciparum positive and negative samples when nPCR was applied for all ICT positive, co-infected and negative samples. 